This item was submitted to Loughborough's Research Repository by the author.

Items in Figshare are protected by copyright, with all rights reserved, unless otherwise indicated.

\title{
Disentangling environment-specific sustainability-oriented innovation: insights from the Airbus-Boeing duopoly
}

PLEASE CITE THE PUBLISHED VERSION

https://doi.org/10.1007/978-3-319-93212-5

\section{PUBLISHER}

Palgrave Macmillan (c) The Authors

\section{VERSION}

AM (Accepted Manuscript)

\section{PUBLISHER STATEMENT}

This book chapter was accepted for publication in the book de Boer, L. and Houman Andersen, P. (eds). Operations Management and Sustainability and the definitive published version is available at https://doi.org/10.1007/978-3-319-93212-5

\section{LICENCE}

CC BY-NC-ND 4.0

\section{REPOSITORY RECORD}

Nishant, Rohit, Alok Choudhary, Hung Yao Liu, and Mark Goh. 2018. "Disentangling Environment-specific Sustainability-oriented Innovation: Insights from the Airbus-boeing Duopoly". figshare. https://hdl.handle.net/2134/35092. 


\title{
9. Disentangling Environment Specific Sustainability - Oriented Innovation: Insights from the Airbus-Boeing Duopoly
}

\author{
Rohit Nishant (Rohit.nishant@esc-rennes.com) \\ ESC Rennes School of Business, Rennes, France \\ Alok Choudhary (A.Choudhary@lboro.ac.uk) \\ School of Business and Economics, Loughborough University, UK \\ HungYaoLiu(iselhy@nus.edu.sg) \\ Department of Industrial Systems Engineering and Management \\ National University of Singapore, Singapore \\ Mark Goh \\ NUS Business School and The Logistics Institute-Asia Pacific \\ National University of Singapore, Singapore
}




\begin{abstract}
We develop an empirically grounded understanding of Environment Specific SustainabilityOriented Innovation (ES-SOI) in the technology-intensive aviation industry. Focusing on the Boeing - Airbus duopoly, we use secondary and archival data from several sources (e.g., sustainability reports and databases). Methodologically, manual coding and centering resonance analysis (CRA) based clustering techniques are used to arrive at distinct types of ES-SOI. Specifically, resource consumption and resource efficiency are salient in the ESSOI. We conclude with how these distinct ES-SOIs could extend theoretical deliberations on the SOI.
\end{abstract}

Keywords: Sustainability, Innovation, Environment, Aviation, CRA 


\section{Introduction}

Sustainability-Oriented Innovation (SOI) is defined as "making intentional changes to an organization's philosophy and values, as well as to its products, processes or practices, to serve the specific purpose of creating and realizing social and environmental value in addition to economic returns" (Adams et al., 2015:2). SOI differs from general innovation in its focus on social and environmental values. With SOI's increasing importance and popularity, it is important to answer a critical question i.e. what SOI consists of. Focusing on one of SOI's major components, we consider disentangling environment-specific SOI (ES-SOI) as our first step towards answering that critical question. The existing literature also prompts the need for a detailed investigation of various types of ES-SOI, in general, to help researchers to comprehend, analyze, and explain complex realities as thoroughly as possible. Addressing this research gap, our main goal is to develop an empirically grounded understanding of Environment Specific Sustainability-Oriented Innovation (ES-SOI). More importantly, this research seeks to investigate if the ES-SOI conceptualized in recent research is adopted in practice and as a result extends our understanding of SOI in general and ES-SOI in particular.

With a growing concern over global warming and climate change, firms are increasingly expected to improve their environmental sustainability, either by optimizing resource consumption or by increasing resource efficiency. These actions help these firms to reduce further environmental footprint measured in terms of carbon dioxide $\left(\mathrm{CO}_{2}\right)$ and other greenhouse gases (GHGs) emissions. In other words, firms are recognized as a part of the solution, instead of being the problem, to facilitate environmental sustainability (Simanis and Hart, 2009). At the core of this solution lies the ES-SOI, which can reduce the environmental footprint of firms' operations. Studies such as Adams et al. (2015) conceptualize SOI as 
innovations that create social and environmental values beside economic values. ES-SOI is a subset of this broader conceptualization of SOI with a specific focus on generating environmental values. Research in the domain of environmental sustainability emphasizes the role of changes in technology, processes, and product as key to achieving the goal of environmental sustainability.

Sustainability has been the topic of research for over three decades (Bansal and Hoffman, 2012). Past studies on corporate sustainability have often invoked theoretical frameworks such as Hart's Quadrant (1997) and the theoretical lenses such as the Natural-ResourceBased View (NRBV). NRBV, as well as Hart's Quadrant, emphasize on clean technology and process improvement in the form of pollution prevention and product stewardship (Hart and Dowell, 2011) as ways to achieve the goal of environmental sustainability. Besides the theoretical frameworks that emphasize different dimensions of sustainability, there has been the ongoing conceptual development of SOI (Adams et al., 2015). We follow the studies that conceptualize SOI and contend that ES-SOI manifest in a firm's processes and products are instrumental to environmental sustainability. Our main goal in this study is to empirically investigate if the conceptualization of ES-SOI as observed in existing literature is evident from a firm's innovations.

As for the empirical context, we investigate the aviation industry. If the aviation industry were a country, it would rank 21 st in the world, in terms of the gross domestic product, generating US $\$ 606$ billion annually (ATAG, 2017). However, the aviation industry is also responsible for $2 \%$ of all human-induced $\mathrm{CO}_{2}$ emissions or about $12 \%$ of $\mathrm{CO}_{2}$ emissions from all transport sources (ATAG, 2017). Consequently, firms in this sector face institutional pressure to engage in activities that reduce the sectoral carbon footprint and develop 
environment-friendly products and processes. Therefore, the aviation industry serves as a suitable candidate for our analysis. In addition, the aviation industry being a technologyintensive sector presents an opportunity for firms to innovate. Hence, studying this sector helps us to examine the upper bound of the ES-SOI phenomenon.

Our contribution is threefold. Firstly, we develop an empirically grounded understanding of ES-SOI. Some studies have proposed typologies for innovation such as Hipp and Grupp (2005), Damanapour (2014), and Roscoe et al. (2016) to develop an understanding of SOI. However, these studies are conceptual and are not empirically grounded. Besides, they focus on SOI in general. In contrast, we examine the ES-SOI practices in particular and use empirical methods to understand ES-SOI and analyze if the ES-SOI practiced by firms are consistent with the conceptualizations of broader SOIs, as proposed in prior studies. The proposed ES-SOI analysis enhances our understanding of SOI by delineating its construction and boundaries. This contribution also responds to a recent call by scholars such as Adams et al. (2015), who highlighted the need for an empirical understanding of SOI, in general, to further appreciate organizational behavior, and Girotra and Netessine (2013), who encouraged the empirical examination of SOI in the operations management domain.

Secondly, we further deliberate about how the various types of ES-SOI observed in our empirical setting might impact environmental sustainability. The outcome of this investigation would assist practitioners in decision making, especially on their prioritization of the ES-SOI practices. Finally, we also deliberate various theoretical frameworks that could help us to develop a comprehensive understanding of ES-SOI. Research has often argued for the salience of context in organizational behavior (Johns, 2006). Recognizing this, we contextualize our study in a unique empirical context. The findings from this study can offer 
insights for other technology-intensive sectors, which are slowly replacing the conventional manufacturing sectors.

This chapter is organized as follows. First of all, we introduce the context and the need for proposed research. Next, we survey the extant literature to identify the existing research gaps. After that, we present the research methods used for our exploratory analysis. Our results on the ES-SOI analysis and the link between ES-SOI and environmental sustainability are presented with a short discussion. The chapter concludes with some limitations of our study and directions for future research.

\section{Literature Review}

The past three decades have seen a plethora of studies in the domain of sustainability (Hoffman and Bansal, 2012). A number of these studies often focused on establishing the linkages between environmental sustainability and financial performance linkage, and have reported mixed findings (Sarkis et al., 2011). An extensive review of the existing body of literature revealed that there is a dearth of studies on SOI in general and ES-SOI in particular. Besides, there are limited studies on the ES-SOI and environmental sustainability linkage. Earlier studies focusing on SOI suggest that SOI is related to the product, process, and organizational innovation. Like sustainability, SOI is a multi-dimensional concept comprising the dimensions of environmental, social, and economic values. In particular, the ES-SOI is focused on the environmental dimension. However, there is a lack of empirical research related to ES-SOI. This creates a research gap that needs to be addressed and justifies our focus on the ES-SOI. Moreover, studies on SOI have restricted their focus to a narrow range of innovations such as products and technologies (Adams et al., 2015). Such a 
focus is too broad. Environmental sustainability, however, is focused on aspects such as emissions, water, and waste. Consequently, there is a need to pay specific attention to ESSOI.

Previous studies examining SOIs have highlighted three SOI dimensions, namely, technical/people; insular/systemic and stand-alone/integrated (see Figure 9.1) (Adams et al., 2015). The innovation focus could be on people or technology (Baumann et al., 2002). In contrast to technology-centered innovation, people-centered innovation views innovation as a complex construct that involves the interplay between people, policies, and systems. Insular innovation is focused on specific firms to address the issues and concerns relevant to them. In contrast, systematic innovation has implications beyond the firm's boundary, on the wider socio-economic system (Baumann et al., 2002). Stand-alone innovation would be restricted to a specific department or function in a firm, whereas integrated innovation would comprehensively and seamlessly extend across the firm.

Since SOI dimensions are focused on innovations in general, we argue that there is a need to develop the understanding of ES-SOI beyond dimensions identified in the SOI studies. We empirically examine the ES-SOI practices of firms. Specifically, we examine if there are any salient characteristics associated with ES-SOI. The rationale is that nuances such as the salience of specific natural resources in different innovations would not be visible in broader SOI-focused classifications such as stand-alone or integrated. This would conceal a key aspect, namely, natural resource accounting, which could be salient in ES-SOI. 


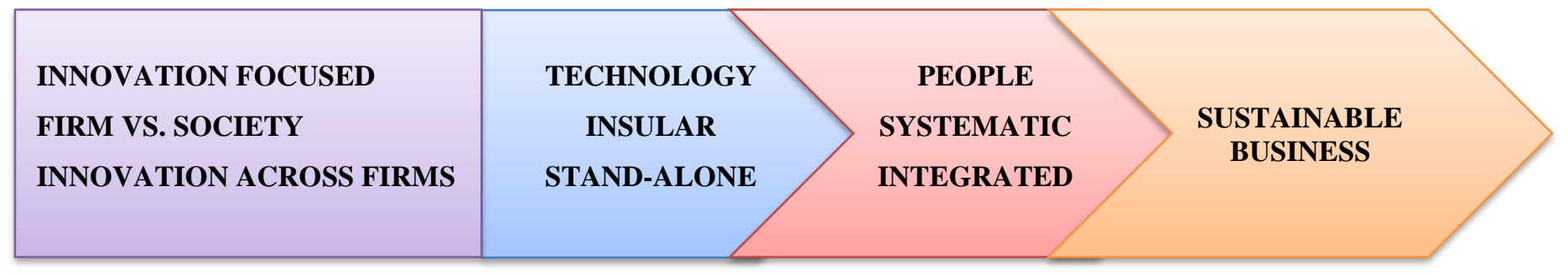

Figure 9.1 Different SOI dimensions (Adapted from Adams et al., 2015)

Studies such as Adams et al. (2015) have also identified a need to recognize the salience of specific contextual elements and nuances in SOI. The abovementioned limitations of the existing body of literature motivate the use of secondary databases, application of different methodologies, and focus on a specific sector to develop a better understanding of the ESSOI phenomenon.

\section{Research Approach}

\section{Aviation Industry}

We contextualize our study in the aviation sector. The aviation sector makes an interesting testbed, as this sector relies heavily on innovations. As discussed, the environmental footprint of this sector necessitates ES-SOI.

There are two main civilian aircraft manufacturers, Boeing and Airbus (EADS). These companies effectively make the aviation industry a duopoly (Datamonitor, 2008). Indeed, Boeing and Airbus account for about $94 \%$ of the global passenger capacity, or available seat kilometers (Innovata, 2015). In addition, the aviation industry is highly technology intensive, for reasons of safety, cost, and product development. Constant innovation is needed to bring to bear on the final products made by Boeing and Airbus to ensure that the airlines receive environmentally smarter and socially acceptable aircraft. Thus, it is reasonable for our research to focus only on Boeing and Airbus, and overlook the other small players such as 
Embraer. The ES-SOI in the aviation sector would have a significant influence on sectoral emissions and resource consumption.

\section{Data}

The data used in this study are mainly unstructured qualitative data from archival reports from different sources. In particular, we use the sustainability reports from Boeing and Airbus as well as their responses to the Carbon Disclosure Project questionnaire. We also use the Advisory Council for Aviation Research and Innovation in Europe reports, WIPO's PatentScope database, and the Aviation Week archives. Nevertheless, our analysis is primarily concentrated around the sustainability reports.

Analysis

To disentangle the ES-SOI, we adopt both manual coding and text-mining techniques to ensure the robustness of our analysis. For manual coding, one of the authors manually analyzed the participating firms' ES-SOI practices and classified them according to their characteristics (e.g., product/process innovation and focus areas).

For the text mining qualitative technique, we utilized centering resonance analysis (CRA). First, we analyzed every innovation description using CRA to find out the influential keywords. We retained innovations with a focus on environment as our study is centered on ES-SOI. Thereafter, we use CRA to classify the different ES-SOI into thematic areas. Each theme reveals distinct characteristics of the ES-SOI innovations. We specifically applied hierarchical cluster analysis based on the CRA to classify the ES-SOI reported by our sampled firms. CRA analyzes text by finding the main concepts and terms based on their "betweenness" centrality. More details of this technique can be found in Corman et al. (2002). 
The hierarchical cluster analysis classifies the texts into clusters based on the similarity or resonance between different texts, which reflect the various innovations

\section{Results}

Our preliminary empirical analysis comprises of the following steps: we first examine sustainability reports and other unstructured data sources, study specific instances of a firm's ES-SOIs, and analyze their specific characteristics. We follow up this examination with the reflection of the linkage of specific ES-SOI with different aspects of environmental sustainability. We examine the various theoretical lens that could explain ES-SOI. We also investigate whether or not our empirical analysis extends these theoretical lenses or perhaps there is a need to develop new theoretical lenses to better understand ES-SOI. The following presents our results after the analysis of the ES-SOI analysis.

\section{Manual Coding}

To disentangle the ES-SOI, we analyzed various reports from 2007 to 2014, spanning 8 years of public data. Following Montabon et al. (2007) and Tate et al. (2010), we specifically focused on changes in processes and products that targeted improving environmental performance. Our manual coding reveals the following practices adopted by Boeing.

"Boeing's newest airplanes, the 787 Dreamliner and the 747-8, exemplify the company's dedication to environmental design innovation. ....-the 787 is designed for the environment with an impressive 20 percent improvement in fuel use and ... reduction in carbon dioxide emissions compared ... airplanes" (Boeing Sustainability Report 2009).

\footnotetext{
${ }^{1}$ Firms publish their sustainability reports under various titles such as environment report and csr report. Reports by major firms often follow Global Reporting Initiative (GRI) guidelines.
} 
Boeing focused on design innovation with the specific objectives of improving fuel efficiency and reducing carbon footprint. Such an innovation focus is externally oriented to improve the environmental sustainability of the airlines. Moreover, Boeing has also started focusing on the control systems used by the air-traffic controllers. While the focus is still external, but the innovation is centered on the non-aircraft manufacturing activities.

"Boeing has tested enhanced air traffic control systems at major airports in .... ... annual fuel consumption .... ...., airlines would reduce annual emissions .... .... urge governments to update aging air traffic control systems." (Boeing Sustainability Report 2010)

More recently, Boeing has been focusing on new milestones such as next-generation technology, e.g., space technology. Thus, Boeing's focus on innovation has enlarged from design to next-generation technologies.

"Boeing is building a better planet thanks to innovations such as the world's first allelectric propulsion satellite. The all-electric propulsion design of the 702SP (small platform) satellites gives customers new flexibility and next-generation technology for increased performance, more affordable launch options and the ability to nearly double payload capacity." (Boeing Sustainability Report 2014)

Furthermore, Boeing is focusing on internally focused innovations such as combining lean practices with process improvement to reduce its carbon footprint.

"Our commitment ... environmental improvement ... ...., from expanding ISO 14001 certification to additional sites and subsidiaries to finalizing clean up at 12 remediation sites, to continuing to implement Lean+innovations to reduce waste and improve business performance." (Boeing Sustainability Report 2010)

In comparison, Airbus is also focusing on innovation on several fronts. One of the internal focused innovations in Airbus is the use of robotics and automation technology. 
"A concept called 'Future Factory' is bringing major .... Robots, under direct control of workers using virtual reality technology, will execute assembly tasks in ..... Airbus plans to use these 'cobots' - an acronym for 'cooperative-robot' from the end of 2015 on the A380 programme. Three-dimensional printing is being developed...., cutting waste, production time and costs." (Airbus Sustainability Report 2014)

Like Boeing, Airbus is also focusing on products that reduce the airlines' carbon footprint. Airbus is focusing on eco-efficiency and materials that are more efficient. As a long-term vision, it is also focusing on high speed air travel.

"Advances in materials ...making aviation more eco-efficient. In 2014, Airbus Group Innovations unveiled a new process for creating lightweight hybrid-construction materials. The Stingtech process .... Thanks to this technology, a jetliner's reinforcing stringers and approximately 50\% of its strengthening frames should no longer be necessary..."... The vision of high-speed, low emissions transport ... long-term goal. The Group is working .. international research organisations ... ground-breaking hypersonic flight technology at speeds of up to Mach 6. The collaboration builds on the Group's ZEHST (Zero Emission High-Speed Transport) concept, a visionary highspeed commercial aircraft ... three hours." (Airbus Sustainability Report 2014)

Thus, the manual coding reveals a wide gamut of innovations used in the aviation sector.

CRA Analysis

We followed our manual analysis with CRA analysis. CRA has been utilized in past studies in the domain of sustainable OM such as Tate et al. (2010). We first explored the hierarchical cluster analysis to discover clusters of ES-SOI (if any) in the various innovations conducted by Boeing and Airbus.

Our analysis has identified three clusters in our datasets. The reader may wish to note that each cluster corresponds to specific ES-SOI reported by the responding firms. The CRA 
algorithm identifies three clusters based on the similarity or resonance score, and the distance between the clusters as the optimum number of clusters.

Hence, there are several unique types of innovation. Since our hierarchical clustering analysis has revealed clusters in the text data, we now identify the key themes, which are observed in the clusters. These themes are coherent groups of words that are observed in different groups (clusters) of documents. We used CRA to identify the key themes. We observed that distinct words correspond to different clusters. For instance, for one cluster, the key theme was to focus on fuel. For another cluster, the key theme was to focus on technology such as propulsion technology. For the third and final cluster, the focus was on specific components of an aircraft such as engines.

We further examined the various influential word pairs for different groups of unstructured data sources (See Table 9.1 for influential words in cluster focused on fuel). For instance, we found that fuel is the most influential word for one cluster, and the influential word pairs include fuel in combination with the other words. The influential word pairs indicate that ES-SOI related to fuels focus on reducing fuel quantity. The analysis of words related to technology indicates a focus on technological solutions to improve fuel and energy efficiency and subsequently reduce the carbon footprint. The analysis of words related to aircraft components indicates a focus on specific aspects such as engine and aircraft design to improve the overall carbon footprint.

Broadly, our analysis suggests that ES-SOI innovation is focused on reducing resource consumption and increasing resource efficiency. 


\begin{tabular}{|ll|}
\hline Words & Pairs \\
fuel 0.61122 & fuel | research 0.299 \\
research 0.24462 & fuel | sufficient 0.107 \\
Sufficient 0.1754 & fuel | development 0.067 \\
quantity 0.12097 & fuel | industrialisation 0.064 \\
centre 0.12097 & fuel | sustainable 0.063 \\
group 0.11358 & fuel | low 0.056 \\
development 0.11022 & fuel | biomass 0.048 \\
industrialisation 0.10517 & fuel | numerous 0.038 \\
\hline
\end{tabular}

Table 9.1 - Identification of Key Terms and Themes in Different Innovations by CRA

The findings from the CRA application reinforce our findings of manual analysis in the previous sub-section, which indicated that there are several innovations focused on fuel. Manual coding also showed that there are several innovations focused on technological improvement. We also observed that there is an increasing focus on specific aspects such as aircraft design. There also seems to be a focus on the lifecycle approach towards aircraft manufacturing. Apparently, there is the adoption of concepts such as Design for Environment (DfE) by the firms. In this way, the application of multiple methods leading to similar findings demonstrates the robustness of our results.

\section{Implications for Research and Practice}

Past studies conceptualize SOI along three dimensions and proposed dichotomous classifications such as technology or people oriented, stand-alone or integrated, and systematic or insular. Our exploratory analysis suggests that ES-SOI can be approached from distinct perspectives such as resource consumption and resource efficiency, which seem to 
be salient in the ES-SOI. Another perspective, which is evident in ES-SOI, is the design perspective as firms are focusing on DfE. Approaching ES-SOI from these perspectives could extend our understanding of ES-SOI more comprehensively as delineating ES-SOI solely into technology, and people oriented solutions could obfuscate the intertwined technology and people's orientation of ES-SOI. Even a technology-oriented ES-SOI would require people orientation to achieve the goal of environmental sustainability. Technologyoriented SOI in the absence of people orientation could fail to achieve success in meeting the environmental sustainability objective due to poor adoption and execution by stakeholders such as employees. We also did not observe the predominance of stand-alone innovation. This phenomenan could be perhaps attributed to the characteristics of the studied sector. Our findings thus indicate that we can develop our understanding of ES-SOI in the technologyintensive sector by focusing on specific resources that these ES-SOI targets. Firms are increasingly focusing on integrated solutions and innovations. Consequently, a specific focus on the targeted resource could help comprehend the salient characteristics of ES-SOI in a better manner. Given the complexity of modern supply chain and strong relationship between the original equipment manufacturers (OEMs) (here Boeing and Airbus) with their suppliers, the innovations, in general, are expected to be relatively less insular. The aviation sector has high safety and technological requirements, which necessitate the strong relationships and interdependencies. This also results in the strong potential for spill-overs. Research focusing on systematic and insular innovation dichotomy could approach innovation from the supply chain relationship perspective to understand the rationale underlying the dominance of one form of innovation over another.

To summarize, our preliminary analysis suggests that approaching ES-SOI from resource perspective could enhance our understanding, but we recognize that this study is (i) 
exploratory, and (ii) we have taken the liberty to extend the conceptualizations of SOI to focus on the aviation industry, which is highly technology intensive, and will grow to be a more popular mode of transport in the future.

The distinct focus of the three clusters that emerged in our analysis could also have different consequences regarding environmental sustainability. The ES-SOI focused on fuel would help firms specifically in reducing the carbon footprint of fuel consumption directly. In contrast, technology-focused ES-SOI would have an indirect impact on the carbon footprint. The third cluster of ES-SOI would influence the carbon footprint through reducing the negative consequences of the complete lifecycle of the aircraft.

We recognize that the ES-SOI and ES linkage could certainly be driven by clean technology investments, but the focus on organizational and human capital related aspects must not be overlooked. It is in the interest of practice and managers to have the final say in determining how the continuum of innovations should be navigated given the availability of resources. Broadly, the technology orientation of ES-SOI in the aviation sector indicates that such innovation could be categorized as clean technology. Due to inherent focus of specific instances of ES-SOI on reducing carbon footprint and approaching the products from lifecycle perspectives, they can be also sub-categorized as pollution prevention and product stewardship.

\section{Concluding Remarks}

In this chapter, we use the example of two major players in the aviation manufacturing sector to highlight the need for a better understanding of appropriately marrying sustainability oriented innovation with environmental sustainability. However, we hope that the outcome 
of our research can help to develop a better understanding of the state of play in the ES-SOI and environmental sustainability domains.

Our study has its limitations. It is contextualized in one unique industry setting. Therefore, the findings of this research cannot be readily generalized to other industries. Nevertheless, our study could reveal the nuances associated with ES-SOI, and therefore contributes to our understanding of this emerging phenomenon. It extends the existing studies such as Adams et al. (2015). Future research could specifically focus on distinct resources as they emerged as the key focus of ES-SOI.

\section{References}

Adams, R., Jeanrenaud, S., Bessant, J., Denyer, D. \& Overy, P. (2015). "Sustainabilityoriented innovation: a systematic review," International Journal of Management Reviews. Forthcoming.

ATAG (Air Transport Action Group). (2017). Available at: http://www.atag.org/facts-andfigures.html. (Accessed 15 ${ }^{\text {th }}$ Dec 2017).

Bansal, P., \& Hoffman, A. J. (Eds.). (2012). The Oxford Handbook of Business and the Natural Environment. Oxford University Press.

Baumann, H., Boons, F. \& Bragd, A. (2002). "Mapping the green product development field: engineering, policy and business perspectives," Journal of Cleaner Production, Vol. 10, No. 5, pp. 409-425.

Corman, S.R, Kuhn, T., McPhee, R.D. \& Dooley, K.J. (2002). “Studying complex systems centering resonance analysis of communication," Human Communication Research, Vol. 28, No. 2, pp. 157-206.

Damanapour, F. (2014). "Footnotes to research on management innovation," Organization Studies, Vol. 35, No. 9, pp. 1265-1285.

Girotra, K. \& Netessine, S. (2013). "OM forum-business model innovation for sustainability," Manufacturing \& Service Operations Management, Vol. 15, No. 4, pp. 537-544.

Hart, S.L. (1997). "Beyond greening: strategies for a sustainable world," Harvard Business Review, Vol. 75, No. 1, pp. 66-77.

Hart, S.L. \& Dowell, G. (2011). "Invited editorial: a natural-resource-based view of the firm fifteen years after,” Journal of Management, Vol. 37, No. 5, pp. 1464-1479. 
Hipp, C. \& Grupp, H. (2005). "Innovation in the service sector: the demand for servicespecific innovation measurement concepts and typologies," Research Policy, Vol. 34, No. 4, pp. 517-535.

Johns, G. (2006). "The essential impact of context on organizational behavior," Academy of Management Review, Vol. 31, No. 2, pp. 386-408.

Montabon, F., Sroufe, R., \& Narasimhan, R. (2007). "An examination of corporate reporting, environmental management practices and firm performance," Journal of Operations Management, Vol. 25, No. 5, pp. 998-1014.

Roscoe, S., Cousins, P.D. \& Lamming, R.C. (2016). "Developing eco-innovations: a threestage typology of supply networks," Journal of Cleaner Production, Vol. 112, pp. 19481959.

Simanis, E., \& Hart, S. L. (2009). "Innovation from the inside out," MIT Sloan Management Review, Vol. 50, No. 4, p. 77.

Tate, W. L., Ellram, L. M., \& Kirchoff, J. F. (2010). “Corporate social responsibility reports: a thematic analysis related to supply chain management," Journal of Supply Chain Management, Vol. 46, No. 1, pp. 19-44. 